\title{
A Device for Respiratory Monitoring during Nutritive Sucking: Response to Neonatal Breathing Patterns
}

\author{
Andrea Rosi, ${ }^{1}$ Emiliano Schena, ${ }^{1}$ Carlo Massaroni, ${ }^{1}$ Eleonora Tamilia, ${ }^{2}$ \\ Domenico Formica, ${ }^{3}$ and Fabrizio Taffoni ${ }^{3}$ \\ ${ }^{1}$ Research Unit of Measurements and Biomedical Instrumentation, Center for Integrated Research, \\ Università Campus Bio-Medico di Roma, Via Álvaro del Portillo 21, 00128 Rome, Italy \\ ${ }^{2}$ Division of Newborn Medicine, Boston Children's Hospital, Harvard Medical School, 300 Longwood Avenue, Boston, MA 02115, USA \\ ${ }^{3}$ Research Unit of Biomedical Robotics and Biomicrosystems, Center for Integrated Research, Università Campus Bio-Medico di Roma, \\ Via Álvaro del Portillo 21, 00128 Rome, Italy
}

Correspondence should be addressed to Fabrizio Taffoni; f.taffoni@unicampus.it

Received 29 November 2015; Revised 11 February 2016; Accepted 21 February 2016

Academic Editor: Andreas Schütze

Copyright ( 2016 Andrea Rosi et al. This is an open access article distributed under the Creative Commons Attribution License, which permits unrestricted use, distribution, and reproduction in any medium, provided the original work is properly cited.

The quantitative monitoring of breathing, sucking, and swallowing is required to predict newborns' neurodevelopmental outcomes. In particular, the coordination of breathing timing with respect to sucking cycle is crucial. In this work, we present the characterization of a low-cost flowmeter designed for noninvasive recording of breathing pattern during bottle feeding. The transducer is designed to be integrated on a commercial feeding bottle also instrumented with a system for sucking monitoring. The flowmeter consists of two transistors (hot bodies) supplied at constant current, which are placed in a duct used to convey the inspiratory and expiratory flow coming from the newborn's nostrils. The transducer design, its static calibration, and its response time are discussed. Moreover, a custom-made active lung simulator was used to perform a feasibility assessment of the proposed flowmeter for respiratory monitoring of neonatal respiratory patterns. The flowmeter has a discrimination threshold $<0.5 \mathrm{~L} \cdot \mathrm{min}^{-1}$ and a response time of $347 \pm 12 \mathrm{~ms}$. The breathing period estimated by the proposed transducer was compared with the one measured by a high performance flowmeter, used as reference: the mean absolute error was $<11 \%$. Results highlighted the ability of the device to track respiratory patterns at frequencies typical of neonatal breathing.

\section{Introduction}

Coordination of sucking, swallowing, and breathing represents a key competency necessary to develop an efficient and effective nutritive sucking (NS). Its lack may cause aspiration and apnea with short-term clinical problems (as pulmonary diseases) and long-term consequences, as delays in neonatal growing and neurodevelopment [1]. Indeed, a modified neural control of feeding and swallowing may significantly alter the structure and function of the developing brain, delay the attainment of oral-motor skills such as nutritive sucking (NS), and negatively impact the transition to oral feeds $[2,3]$. This is particularly true in preterm and low-birth-weight newborns, who often present problems with autonomous feeding that may be related to the immaturity of their Central Nervous System (CNS) [1-6].
The assessment of feeding performance is widely recognized as very important for discharge timing and as a prospective indicator of medical and developmental progress (or problems) in the weeks after discharge and in later infancy. Yet, in common practice, neonatal feeding assessment is most often highly subjective, with substantial variability of practices across neonatal nurseries.

Several studies have discussed the problem of the objective study of NS from both technological [7] and clinical point of view [8] and highlighted the importance of the concurrent assessment of sucking, breathing, and swallowing to analyze the relation among them.

Breathing during NS has been analyzed using different commercial devices as Fleisch and screen pneumotachographs, ultrasonic flowmeters, variable orifice meters, and hot wire or hot film anemometers $[9,10]$. One of the most 


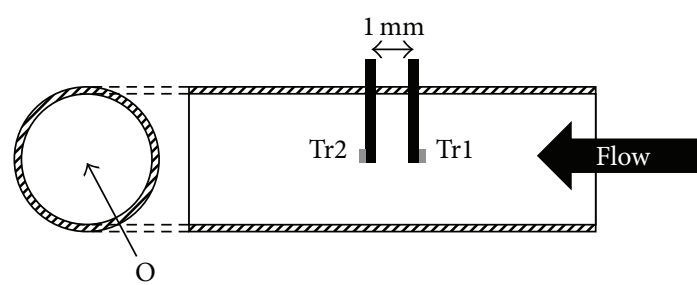

(a)

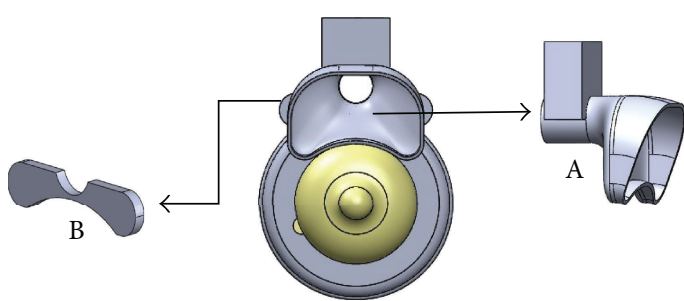

(b)

FIGURE 1: (a) Schematic representation of the hot bodies (two transistors, $\operatorname{Tr} 1$ and $\operatorname{Tr} 2$ ) inside the duct; (b) assembly of mechanical components: (A) duct inserted into the air conveying system with PCBs support and (B) duct support.

common methods used to evaluate nasal airflow and breathing employs a thermistor or a thermocouple placed in a duct below or just inside the nostrils [11, 12].

Many authors have proposed monitoring breathing through the assessment of thoracic movements using mercury-in-rubber and piezo-resistive strain gauges (respiratory bands) placed over the chest and the abdomen [13-15]. More recently, smart textiles based on optical fiber sensors have been proposed to enable respiratory monitoring during Magnetic Resonance Imaging procedures [16]. Our team recently proposed a novel sensor for neonatal breathing monitoring during bottle feeding [17]. Our main goal is to assess the coordination of breathing and sucking during feeding. Feeding is an aerobic activity characterized by a typical alternation of sucking and breathing cycles, which may be modified in preterm and low birth weight infants. This temporal alteration impairs the sucking efficiency and reduces the time spent by the newborn attempting to feed since she/he tires faster.

In this work, after an overview of the working principle, the design, and the fabrication of the sensor (Section 2), we focused on its experimental characterization (Section 3). In particular, we assessed its response time and its ability to estimate the respiratory period simulating typical neonatal breathing patterns. Future testing will evaluate the potential to integrate the investigated transducer with a portable system previously developed to assess sucking pressures in newborns $[18,19]$.

\section{Theoretical Background and Sensor Design}

The proposed transducer is based on the heat exchange between the surfaces of two hot elements (i.e., two transistors) and the gas exhaled and inhaled by the infant (see Figure 1). Thermal sensors have previously been used to estimate breathing flow from heat exchange (see [20]), but this method has been studied further in recent works [21, 22]. In this paper we propose a specific application of this measuring principle to neonatal breathing monitoring. In particular, the proposed sensor detects the gas flow during the breathing phases, thanks to the dependence of the base-emitter voltage $\left(V_{\text {be }}\right)$ on the base-emitter temperature $\left(T_{\text {be }}\right)[23,24]$ which depends in turn on the velocity of the hitting gas. In steadystate conditions, the transistors, placed in a constant fluid stream at temperature $T_{f}$, reach a superficial equilibrium temperature $T_{\text {be }}$ depending on the heat flow $(Q)$ exchanged with the fluid [17]. Thus, $V_{\text {be }}$ can be expressed as a function of the fluid mean velocity $(v)$ :

$$
V_{\mathrm{be}}(v)=a+b\left(\frac{Q}{S(A+B \sqrt{\rho v})}+T_{f}\right) .
$$

The coefficients $a$ and $b$ are constant and $b$ is the thermal sensitivity of $V_{\text {be }}(\approx-2 \mathrm{mV} / \mathrm{K}) . A$ and $B$ are two calibration parameters, $\rho$ is the fluid density, and $S$ is the exchange surface. Two NPN transistors have been placed in the midline of a cylindrical duct, as shown in Figure 1(a). When the gas directly hits the transistor Tr1, its PCB shields the transistor $\operatorname{Tr} 2$. In this case, the $\operatorname{Tr} 1$ reaches an equilibrium temperature lower than the one of $\operatorname{Tr} 2$. The difference between their $V_{\text {be }}$ values can be expressed as

$$
\begin{aligned}
& \Delta V_{\text {be }}\left(v_{1}, v_{2}\right) \\
& \quad=b\left(\frac{Q_{1}}{S\left(A+B \sqrt{\rho v_{1}}\right)}-\frac{Q_{2}}{S\left(A+B \sqrt{\rho v_{2}}\right)}\right),
\end{aligned}
$$

where $v_{1}$ and $v_{2}$ are the velocities of the gas hitting $\operatorname{Tr} 1$ and $\operatorname{Tr} 2$, respectively.

Under laminar flow conditions $(\operatorname{Re}<2000), v_{1}$ is similar to $v_{\max }$ (maximum gas velocity in the duct), where it is about equal to $2 v$ in a cylindrical duct. This hypothesis is justified by the geometry of the duct and the delivered flows described in detail in Section 3. Assuming $v_{2}$ negligible, $Q_{1}=Q_{2}=$ $Q$, and expressing the difference $\Delta V_{\text {be }}$ in terms of volumetric flow rate, (2) becomes

$$
\Delta V_{\text {be }}(F)=b\left(\frac{Q}{S(A+B \sqrt{\rho(2 F / O)})}-\frac{Q}{S A}\right),
$$

where $O$ is the duct cross section and $F=O v$.

This configuration guarantees that one transistor is always directly hit by the gas during all breathing phases and so it allows an effective estimation of the breathing period.

The transducer is composed of two nominally identical NPN bipolar junction transistors (PBSS2515M, Philips), in a SOT883 package $(0.50 \mathrm{~mm} \times 1.02 \mathrm{~mm} \times 0.62 \mathrm{~mm})$ with a default base-emitter temperature junction of $150^{\circ} \mathrm{C}$ and a maximum current collector of $500 \mathrm{~mA}$ [24]. The transistors, used as hot bodies, are supplied by a constant current in common emitter configuration. The two $V_{\text {be }}$ are preprocessed 


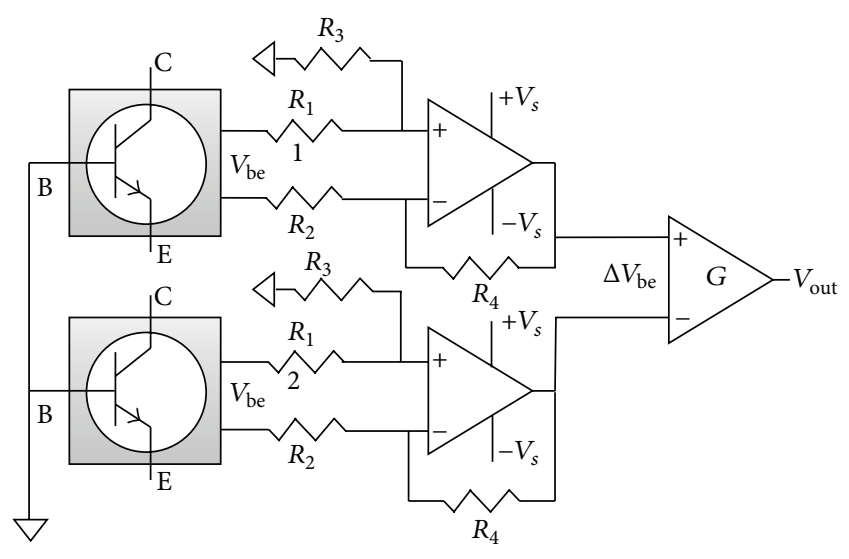

FIGURE 2: Schematic representation of the electric circuit $\left(R_{1}, R_{2}\right.$, $\left.R_{3}, R_{4} \approx 22 \mathrm{k} \Omega, V_{\text {out }}=G \Delta V_{\text {be }}\right)$ to condition signals coming from the $\mathrm{BD}$.

by a low distortion operational amplifier in a differential configuration with unit gain (TL074CN, Texas Instrument); then $\Delta V_{\text {be }}$ is amplified $(G=51)$ by an instrumentation amplifier (INA101HP, Texas Instrument); see Figure 2. The amplification gain is set to work in the linearity region of the amplifier $\left(V_{s}= \pm 12 \mathrm{~V}\right)$.

The two transistors are soldered on two identical PCBs positioned inside a duct at a distance of $1 \mathrm{~mm}$ (Figure 1(a)); this configuration enables (i) reducing cross-talk due to heat conduction between the transistors and (ii) shielding the transistor which is not directly hit by the air flow during breathing. This geometry is designed to be easily integrated into a commercial feeding bottle (angle Well-Being Chicco, Artsana S.p.A.), thus enabling the ecological monitoring of breathing during NS. The end of the duct is connected to a mask designed to match the profile of the feeding bottle and to convey the air during breathing (Figure 1(b)). These mechanical components were designed in SolidWorks and built using a rapid prototyping printer (Project 3000 by $3 \mathrm{~d}$ Printer Inc.) to test the system in laboratory. Air conveying made by soft rubber disposable material will be used with infants in the final application.

\section{Characterization of the Device}

To verify that the theoretical model presented in (3) correctly predicts the actual output of the $\mathrm{BD}$ sensor, preliminary experiments have been carried out. BD sensor was supplied at constant operating current $(500 \mathrm{~mA})$ and connected to a mass flow controller (F-201C-FBC-22-V, Bronkhorst HighTech) by a plastic duct ( $30 \mathrm{~mm}$ of diameter), which avoids any flow leakage. We delivered the following values of flow rates: $0 \mathrm{~L} / \mathrm{min}, 0.1 \mathrm{~L} / \mathrm{min}, 0.2 \mathrm{~L} / \mathrm{min}, 0.5 \mathrm{~L} / \mathrm{min}, 1 \mathrm{~L} / \mathrm{min}, 1.5 \mathrm{~L} / \mathrm{min}$, $2 \mathrm{~L} / \mathrm{min}$, and $2.5 \mathrm{~L} / \mathrm{min}$. The output of the $\mathrm{BD}$ sensor was used to fit the model of (3); see Figure 3. This preliminary analysis confirms the model $\left(R^{2}=0.9913\right)$ and provides a calibration curve for the sensor.

The sensing elements, presented in the previous section, and the mechanical arrangement, properly designed to enable

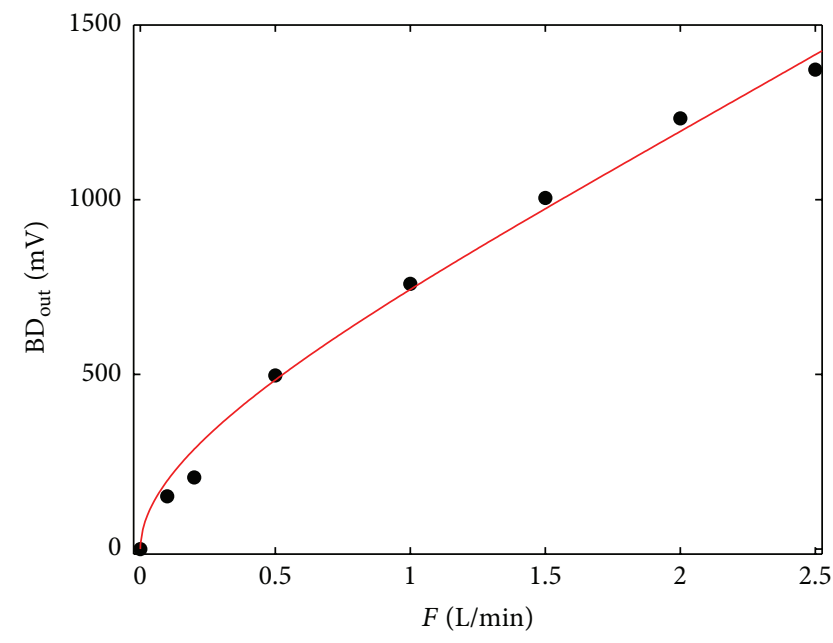

FIGURE 3: $\mathrm{BD}_{\text {out }}$ as a function of flow rate and theoretical model fitting the simulation data.

breathing monitoring during oral feeding (as shown in Figure 1(b)), were tested in order to assess the following features of the system: (i) the discrimination threshold, (ii) the step response, and (iii) the capacity to estimate the breathing period of different respiratory patterns.

The sensing elements were embedded in the air conveying system in order to develop an integrated module to be used during bottle feeding. This breathing device (BD) was interfaced with a nostril simulator made by two pipes of $5 \mathrm{~mm}$ diameter and $15 \mathrm{~mm}$ length; the distance between their centers was $8.5 \mathrm{~mm}$ according to anatomical data [25-27]. The pipes were inserted in a plastic support (Figure 4(b)(C)), which can be used to interface the BD with different testing setups as shown in Figure 4(a). The transducer output $\left(V_{\text {out }}\right)$ was acquired using a data acquisition board (DAQ NI USB6009 , National Instruments) at $1 \mathrm{kHz}$ and sent to a remote laptop for data processing.

In the following subsections, we present the different testing setups used to assess the $\mathrm{BD}$ features.

3.1. Estimation of Discrimination Threshold. A mass flow controller (F-201C-FBC-22-V, Bronkhorst High-Tech) was used to deliver constant flow rates (Figure $4(\mathrm{a})(\mathrm{A})$ ) ranging from $0.1 \mathrm{~L} \cdot \mathrm{min}^{-1}$ to $7 \mathrm{~L} \cdot \mathrm{min}^{-1}$ [28]. Since during bottle feeding the relative position of the nostrils with respect to the $\mathrm{BD}$ may change, the discrimination threshold has been investigated placing transducer at three distances $(10 \mathrm{~mm}, 20 \mathrm{~mm}$, and $30 \mathrm{~mm})$ and at three tilt angles $\left(10^{\circ}, 20^{\circ}\right.$, and $\left.30^{\circ}\right)$ with respect to the simulated nostrils. Distances and tilt angles are illustrated in Figure 5. A micropositioners system (PT1A$1^{\prime \prime}$ Translation Stage, Thorlabs; tilt angle regulator M-481-A series, Newport) was used to adjust the experimental setup in the different configurations.

The distance range investigated allows covering all the working conditions: the minimum distance corresponds to the average distance between the nose and the upper lip of infant as reported in [25-27]; the maximum distance is suggested by the geometry of the considered teat. Angles 


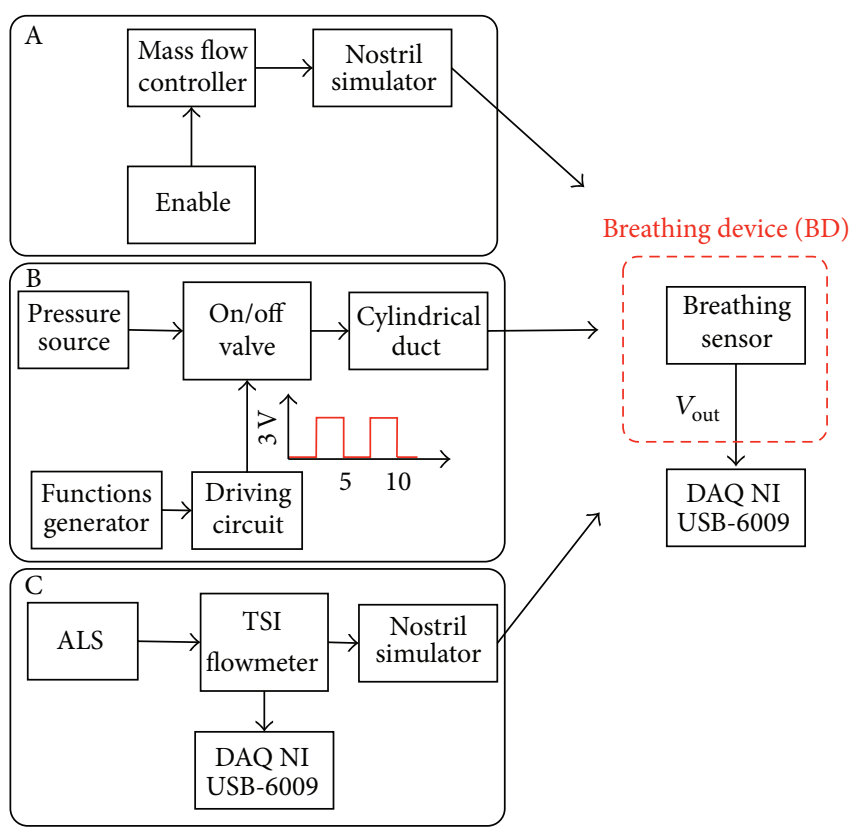

(a)

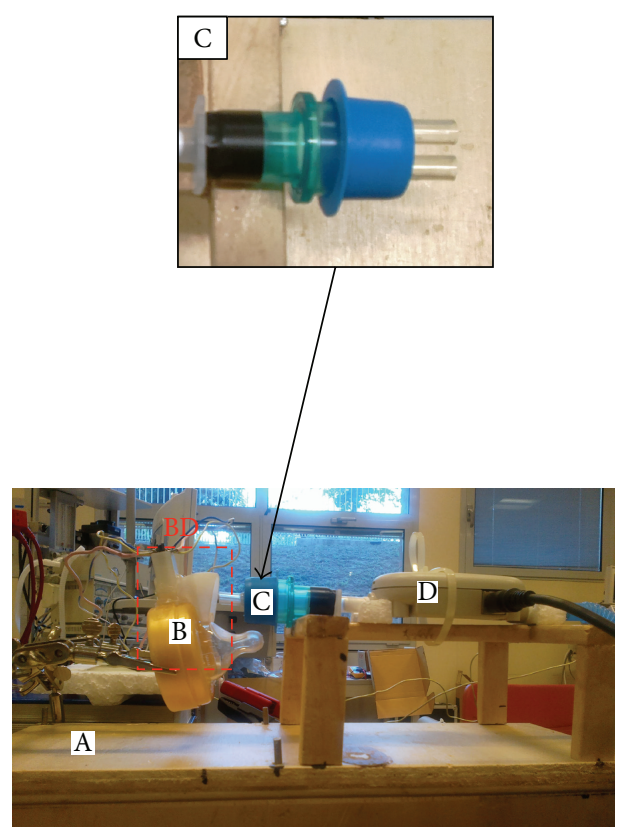

(b)

FIGURE 4: (a) Schematic representation of the setups used to characterize the BD features. (b) Experimental setup with nostril simulator: (A) wood framework $(34.5 \mathrm{~cm} \times 13 \mathrm{~cm} \times 14.5 \mathrm{~cm})$, (B) device with air conveying system, (C) simulated infant's nostrils, and (D) flow meter (4121 TSI).

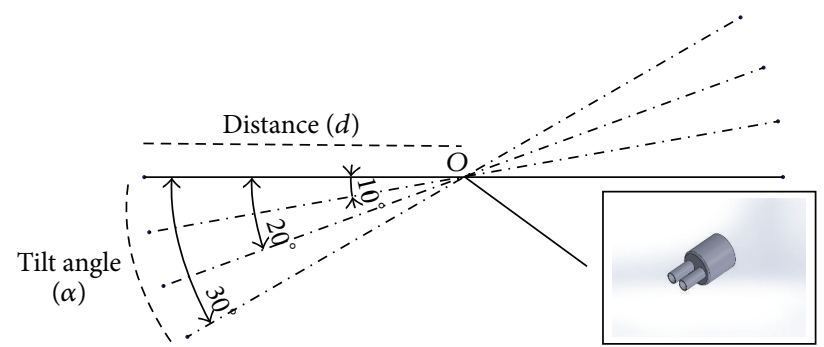

Figure 5: Schematic representation of tilt angles and distances investigated: $d$ is controlled by a translational micropositioner; tilt angles are set using an angular micropositioner, where $O$ is the rotation center.

bigger than $30^{\circ}$ were not investigated as the considered feeding bottle already has its own $30^{\circ}$ tilt. Therefore, these ranges allow covering all the angles and distances, which can occur during bottle feeding [17].

3.2. Step Response Analysis. To assess the step response of the BD, we used an on/off valve (Series 821-2/2 NC, Matrix) coupled with a driving circuit, described in detail in [29] (see Figure 4(a)(B)). A flow rate step was delivered by connecting the valve to a pressurized source and quickly opening or closing the valve's orifice. Thanks to the reduced valve switching time $(<0.45 \mathrm{~ms})$, nominally ideal steps were generated. The electromechanical valve was driven by square waves (frequency $0.2 \mathrm{~Hz}$, amplitude $3 \mathrm{~V}$ ) supplied by a function generator (FG120, YOKOGAWA).
A PVC tube $160 \mathrm{~mm}$ in length and $16.7 \mathrm{~mm}$ in diameter, embedding the transistors, was connected to the valve.

3.3. Estimation of the Breathing Period during Simulated Neonatal Respiratory Patterns. We assessed the capability of the transducer to estimate the breathing period by delivering different respiratory patterns using a custom-made active lung simulator (ALS) [30]; see Figure 4(a)(C). The ALS is able to deliver flows similar to neonatal respiratory patterns in a wide range of frequencies and tidal volumes. In this work we simulated 30 breaths per minute (bpm), $39 \mathrm{bpm}, 45 \mathrm{bpm}$, and $60 \mathrm{bpm} \mathrm{[25]} \mathrm{at} \mathrm{two} \mathrm{inspiratory:} \mathrm{expiratory} \mathrm{ratios} \mathrm{(I:E)}$ (i.e., $1: 1$ and $1: 2$ ) and a fixed tidal volume of $24 \mathrm{~mL}$ (i.e., $8 \mathrm{~mL} / \mathrm{kg}$ for neonatal application) [1]. The results of the BD have been compared with the ones of a fast monodirectional commercial flowmeter (4121 TSI, accuracy of $2 \%$ of measured value, range of measurement up to $20 \mathrm{~L} / \mathrm{min}$, and response time of $4 \mathrm{~ms}$ ), used as reference (Figure 6).

In each trial, ten respiratory acts have been recorded to analyze the repeatability of the system. The flowmeter and BD outputs were recorded using a sampling frequency of $1 \mathrm{kHz}$. Moreover, data have been postprocessed using a virtual lowpass filter (cut-off frequency of $25 \mathrm{~Hz}$ ).

We estimated the breathing period of the two systems (TSI and $\mathrm{BD}$ ), defined as the time between two consecutive local maxima in the corresponding output signal. The peaks were identified by a specific Matlab ${ }^{\circledR}$ function (findpeaks); see Figure 7.

While the temporal pattern of the signal is preserved, the $\mathrm{BD}$ sensor underestimates the flowrate. Actually, this underestimation cannot be considered a measurement error 


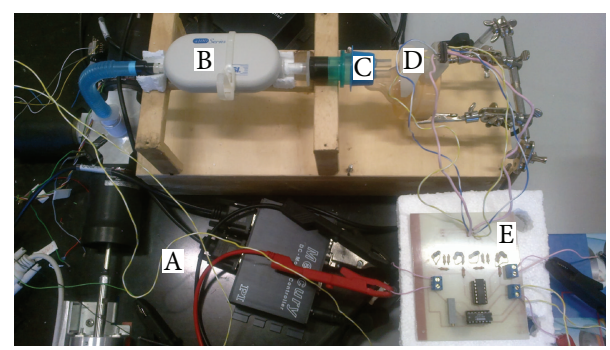

FIgURE 6: Experimental setup to evaluate respiratory patterns: (A) ALS, (B) flow meter 4121 TSI, (C) simulated infant's nostrils, (D) BD, and (E) electronic board for BD signal conditioning.

of the $\mathrm{BD}$, but it is the result of two main causes: (i) air leakage between the nostrils and the air conveying system; (ii) attenuation due to the dynamic response of the $\mathrm{BD}$ sensor.

\section{Results}

4.1. Discrimination Threshold. Measurements have been performed for each air flowrate and for no-flow conditions. For each measurement, lasting $5 \mathrm{~s}$, the average $V_{\text {out }}$ was estimated. Data acquired in no-flow conditions were compared with the ones acquired in case of flow using a $t$-test ( The discrimination threshold was considered as the lowest flowrate for which the $t$-test identifies a significant difference $(p<0.05)$.

Results show that the discrimination threshold mainly depends on the tilt angle. In particular in optimal conditions $\left(10^{\circ}<\right.$ tilt $\left.<20^{\circ}\right)$, the $\mathrm{BD}$ has a discrimination threshold $<$ $0.5 \mathrm{~L} \cdot \mathrm{min}^{-1}$, lower than the infant's minimum expiratory peak (i.e., $1 \mathrm{~L} \cdot \mathrm{min}^{-1}$ ) [31]. A relevant decrease of performances happens at $30^{\circ}$ (see Table 1 ); however, this value represents a borderline case of employment in this kind of application.

4.2. Step Response. Experiments were repeated five times to assess the step response of the BD. The BD output was exponential (see Figure 8(a)); hence we modeled the BD as a first order system and we estimated the response time $(\tau)$ using the function error $\Gamma$ :

$$
\Gamma(t)=\frac{\mathrm{BD}_{\text {out }}(t)-\mathrm{BD}_{\text {out }}(\infty)}{\mathrm{BD}_{\text {out }}(0)-\mathrm{BD}_{\text {out }}(\infty)}=e^{-t / \tau},
$$

where $V(t)$ is the output at time $t, V_{0}$ is the output at $t=0$, and $V_{\infty}$ is the steady-state output. We evaluated the error function in 8 time instants (starting from $t=0$, with steps of $250 \mathrm{~ms}$ ). According to our hypothesis, the natural logarithm of $\Gamma$ results linearly related to time: Figure $8(b)$ shows both experimental data (blue asterisks) and linear fitting (red line) obtained in one of the five experiments. $\tau$ was calculated as the reciprocal of the angular coefficient of the red line. By averaging the values from all the experiments, $\tau$ became equal to $347 \pm 12 \mathrm{~ms}$. The uncertainty was calculated using a Student reference distribution with four degrees of freedom and a $95 \%$ level of confidence, as recommended in [32].
TABLE 1: Estimated threshold $\left[\mathrm{L} \cdot \mathrm{min}^{-1}\right]$ for the three tilt angles and distances investigated.

\begin{tabular}{llcc}
\hline Distance $[\mathrm{mm}]$ & \multicolumn{3}{c}{ Tilt angles $\left[^{\circ}\right]$} \\
& $10^{\circ}$ & $20^{\circ}$ & $30^{\circ}$ \\
\hline 10 & 0.2 & 0.3 & 2 \\
20 & 0.2 & 0.3 & 6 \\
30 & 0.2 & 0.3 & 7 \\
\hline
\end{tabular}

4.3. Breathing Period Estimation. We did not consider the configuration at $30^{\circ}$ of tilt since the discrimination threshold measured for this inclination does not allow an effective monitoring of breathing during sucking (see Section 4.1). Among the other possible configurations, we decided to investigate the one with the worst discrimination performance, that is, the $20^{\circ}$ tilt angle configuration at the three distances $(10 \mathrm{~mm}$, $20 \mathrm{~mm}$, and $30 \mathrm{~mm}$ ).

We estimated the error in measuring the breathing period evaluating the mean absolute error (MAE) between the breathing period measured by $\mathrm{BD}\left(T_{\mathrm{BD}}\right)$ and the one measured by TSI $\left(T_{\mathrm{TSI}}\right)$ as reported in [33]:

$$
\mathrm{MAE}=\frac{1}{n} \sum_{i=1}^{n}\left|T_{\mathrm{BD}}-T_{\mathrm{TSI}}\right|,
$$

where $n$ is the number of acts (i.e., 10). This error has been reported in percentage as

$$
\operatorname{MAE}[\%] \frac{\mathrm{MAE}}{\operatorname{mean}\left(T_{\mathrm{TSI}}\right)} * 100 .
$$

The maximum MAE [\%] was $10.7 \%$ and it was measured at $30 \mathrm{bpm}$, with $\mathrm{I}: \mathrm{E}=1: 2$. The overall results are reported in Table 2. Figures 9 and 10 show the two different breathing patterns assessed by BD and TSI, respectively.

\section{Discussion and Conclusion}

In common practice, the infant feeding assessment is most often highly subjective, with substantial variability of practices across neonatal nurseries. To avoid these issues, a tool for the objective assessment of breathing during feeding may be useful: it may provide indices to estimate feeding performances in terms of coordination between sucking and breathing [34].

In this work, we investigated the application of a noninvasive module to record breathing patterns in newborns during bottle feeding. The transducer is based on the convective heat exchange between the air breathed by the newborn and two transistors. The experimental validation demonstrated that the $\mathrm{BD}(\mathrm{i})$ is able to distinguish flow rate under $0.5 \mathrm{~L} \cdot \mathrm{min}^{-1}$ (with a dependence on the tilt angle between the nostrils and the bottle); (ii) has a response time of about $347 \mathrm{~ms}$; and (iii) allows the estimation of the respiratory period (with a $\mathrm{MAE}<10.7 \%$ ) during the monitoring of neonatal respiratory patterns. Moreover, the proposed BD has been designed to be embedded in a commercial feeding bottle (angle Well-Being Chicco, Artsana S.p.A.), so that such device might enable 


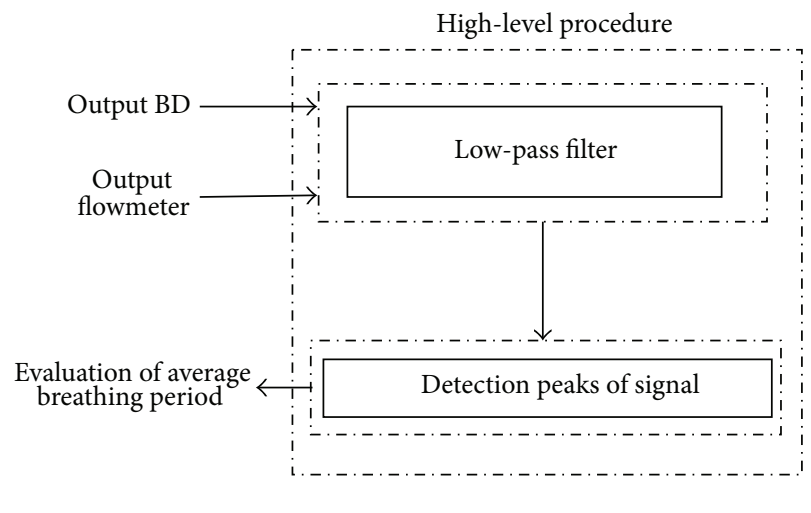

(a)
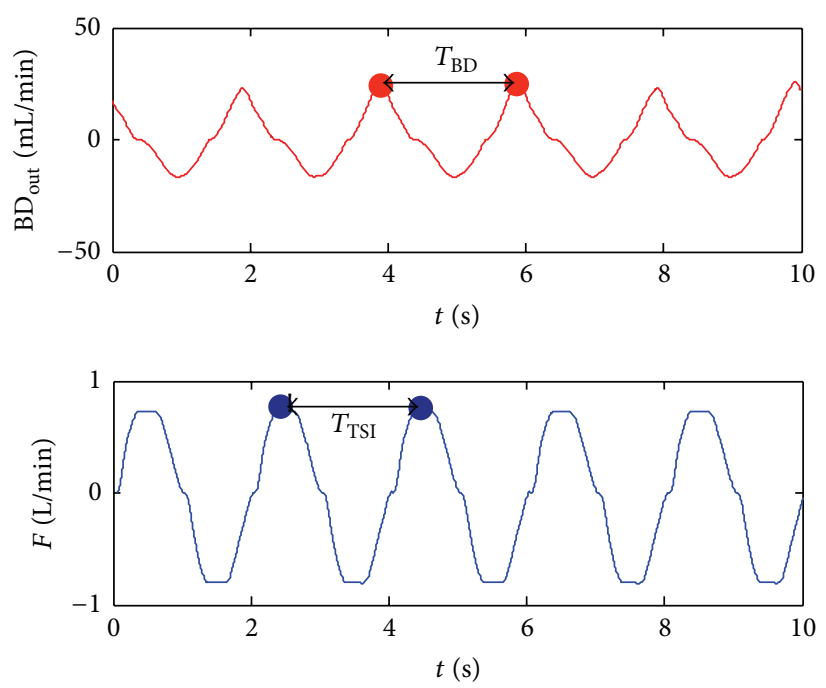

(b)

Figure 7: On (a), a block diagram for breathing period detection and comparison; on (b), an experimental trial of ten acts performed at $0.5 \mathrm{~Hz}(\mathrm{I}: \mathrm{E}=1: 1)\left(T_{\mathrm{BD}}, T_{\mathrm{TSI}}\right.$ are the periods estimated from BD and flowmeter, resp.).

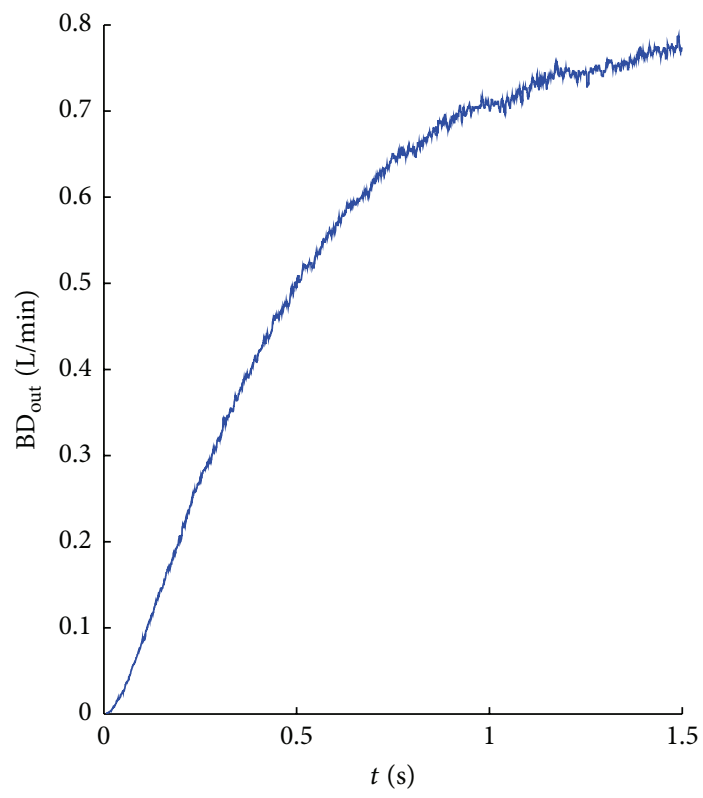

(a)

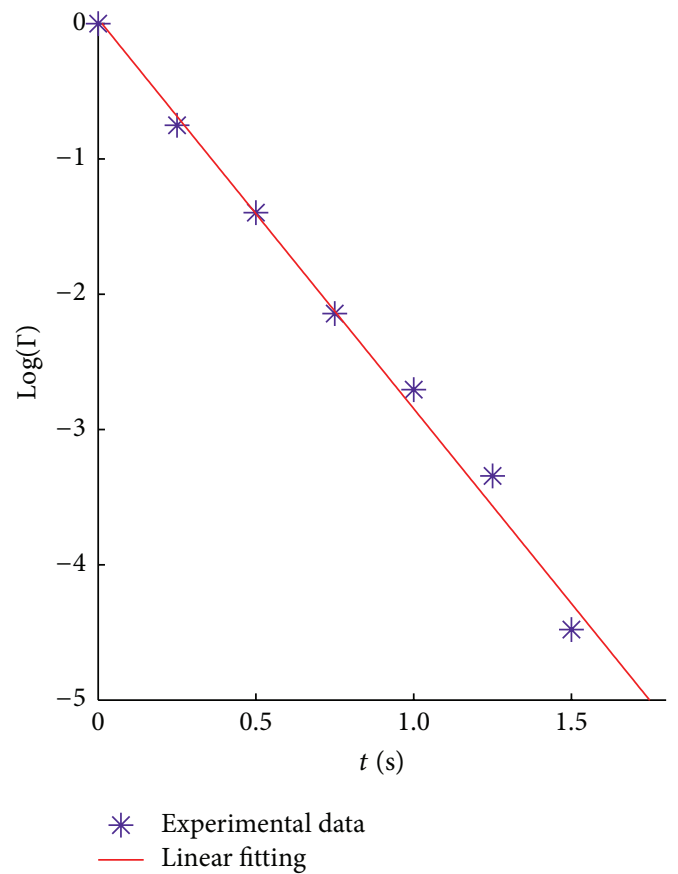

(b)

Figure 8: (a) Step response of the BD sensor; (b) error function assessed in 8 different time instants. Blue asterisks represent the experimental measures while the red line represents the liner fitting $(r=0.9947)$.

noninvasively assessing developmental problems or progress in the weeks after discharge [35].

Several methods have been already proposed to monitor sucking, swallowing, and in particular breathing activities [36-38]. Wang et al. proposed an interesting wireless system to monitor NS and to detect sucking and swallowing events [39]. However, the module for breathing assessment was complex (based on the electromyography) and it did not enable estimating the breathing period.

On the other hand, although other commercial devices (e.g., nasal thermistors or thermocouple, miniaturized pneumotachographs, and hot wire/film anemometers) exhibit high dynamic performances [11, 12, 14, 35, 40, 41], their use often requires invasive procedures which are not suitable for 

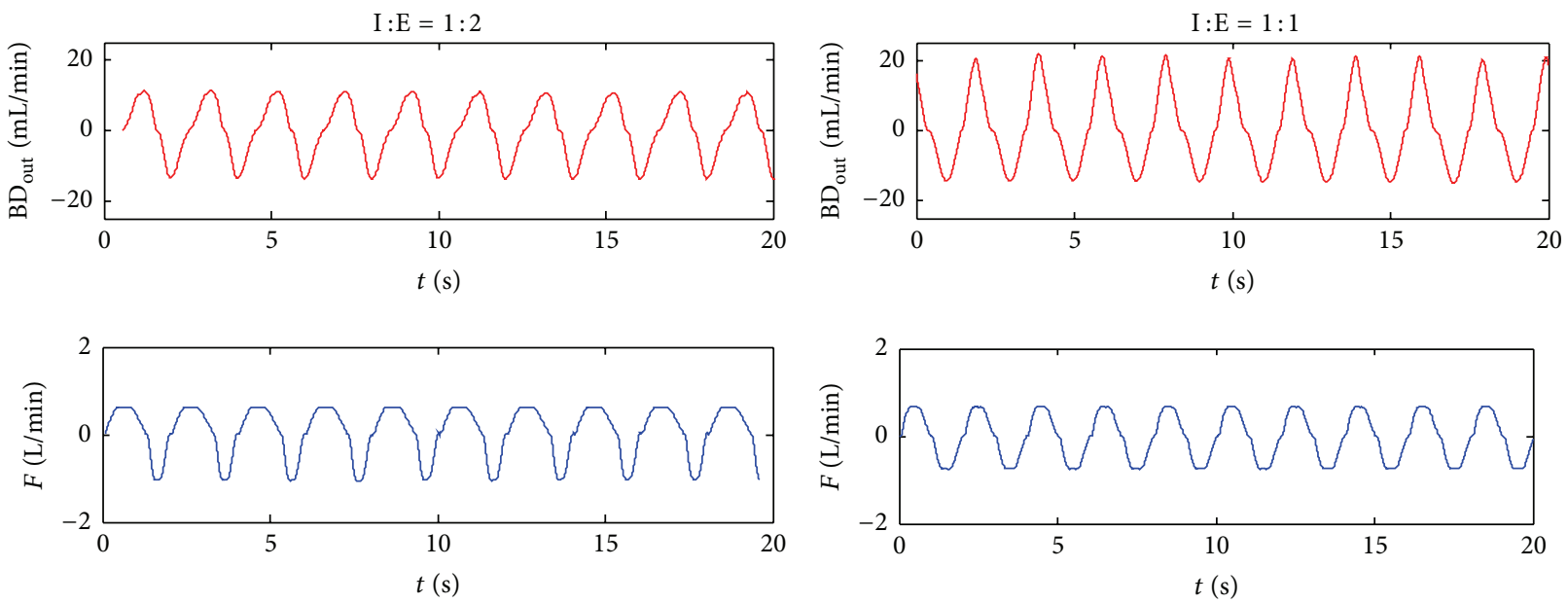

FIGURE 9: Ten acts set at $0.5 \mathrm{~Hz}(30 \mathrm{bpm})$ with two different I: E ratios (the red line is the $\mathrm{BD}$ output and the blue one is the TSI output, resp.).
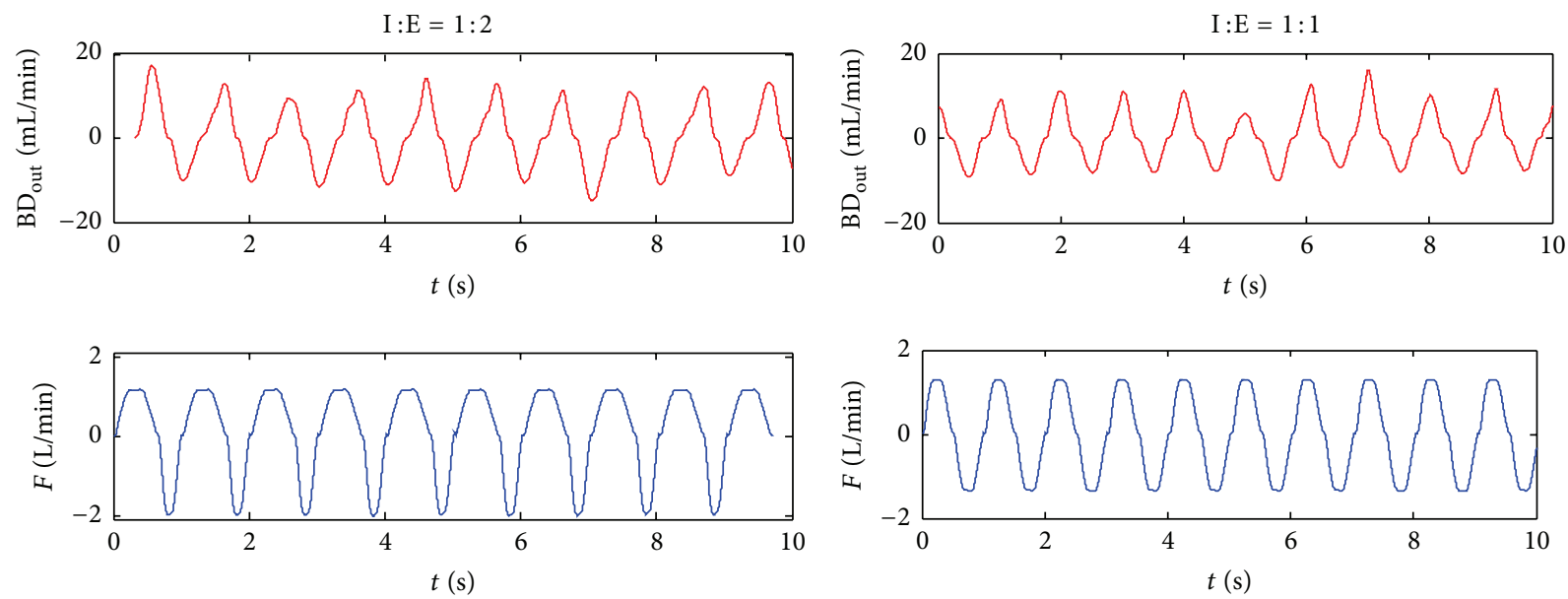

FIGURE 10: Ten acts set at $1 \mathrm{~Hz}(60 \mathrm{bpm})$ with two different $\mathrm{I}$ : E ratios (the red line is the BD output and the blue one is the TSI output, resp.).

TABLE 2: Estimated MAE [\%] for all frequencies and distances investigated.

\begin{tabular}{lccc}
\hline $\begin{array}{l}\text { Frequencies } \\
{[\mathrm{bpm}] /[\mathrm{Hz}]}\end{array}$ & $\begin{array}{c}\text { MAE [\%] } \\
30 \mathrm{~mm}\end{array}$ & $\begin{array}{c}\text { MAE [\%] } \\
20 \mathrm{~mm}\end{array}$ & $\begin{array}{c}\text { MAE [\%] } \\
10 \mathrm{~mm}\end{array}$ \\
\hline \multicolumn{5}{c}{$\mathrm{I}: \mathrm{E}=1: 1$} \\
$30 / 0.50$ & $9.1 \%$ & $4.1 \%$ & $3.4 \%$ \\
$39 / 0.65$ & $5.4 \%$ & $3.8 \%$ & $5 \%$ \\
$45 / 0.75$ & $4.2 \%$ & $5 \%$ & $3.7 \%$ \\
$60 / 1.00$ & $5.1 \%$ & $4.6 \%$ & $4.3 \%$ \\
\hline \multicolumn{5}{c}{$\mathrm{I}: \mathrm{E}=1: 2$} \\
$30 / 0.50$ & $9.3 \%$ & $10.7 \%$ & \\
$39 / 0.65$ & $4.4 \%$ & $7.4 \%$ & $6.2 \%$ \\
$45 / 0.75$ & $2.7 \%$ & $6 \%$ & $2.5 \%$ \\
$60 / 1.00$ & $4.1 \%$ & $3.1 \%$ & $3.3 \%$ \\
\hline
\end{tabular}

at-home applications and which can affect the development of the neural circuits in charge to control the development of sucking and the related sensory integration.
The $\mathrm{BD}$ presented in this work allows estimating the breathing period using a noninvasive low-cost approach. Although the $\mathrm{BD}$ time response is too high to distinguish between inspiration and expiration phase, this sensor can be integrated with a module for sucking assessment, enabling monitoring of typical coordination measurements like the sucking-breathing ratio, and the breathing frequency during nutritive sucking. For this reason we designed the BD to be easily integrated on a commercial feeding bottle to enable large-scale screening of breathing coordination during NS. To this end, the low cost of the components allows the production of disposable devices also reducing the sterilization issues. A redesign of the sensing elements, considering transistors with a smaller package, will allow further improvement of the system performance minimizing the heat inertia and enabling the discrimination between inspiration and expiration.

In conclusion, the experiments we carried out in this work demonstrate the effective applicability of the proposed flowmeter for breathing monitoring during nutritive sucking. The results pave the way to a set of future solutions to 
improve the system performances: in particular, the use of different packages and materials for the case of the sensing elements can improve the dynamic response of the system. Moreover, a real time monitoring of the bottle orientation is also suggested to compensate the negative effect of tilting on the discrimination threshold. These solutions will allow extending the use of the module for breathing monitoring of preterm and low birth weight infants.

\section{Competing Interests}

The authors declare that they have no competing interests.

\section{References}

[1] T. Nieuwenhuis, S. P. Da Costa, E. Bilderbeek, W. B. Geven, C. P. Van Der Schans, and A. F. Bos, "Uncoordinated sucking patterns in preterm infants are associated with abnormal general movements," Journal of Pediatrics, vol. 161, no. 5, pp. 792-798, 2012.

[2] E. T. Rolls, "Smell, taste, texture, and temperature multimodal representations in the brain, and their relevance to the control of appetite," Nutrition Reviews, vol. 62, no. 11, pp. 193-204, 2004.

[3] S. Mistry and S. Hamdy, "Neural control of feeding and swallowing," Physical Medicine and Rehabilitation Clinics of North America, vol. 19, no. 4, pp. 709-728, 2008.

[4] J. M. McGrath and A. V. Bodea Braescu, "State of the science: feeding readiness in the preterm infant," Journal of Perinatal and Neonatal Nursing, vol. 18, no. 4, pp. 353-368, 2004.

[5] P. Dodrill, "Feeding difficulties in preterm infants," Infant, Child, and Adolescent Nutrition, vol. 3, no. 6, pp. 324-331, 2011.

[6] C. M. Craig and D. N. Lee, "Neonatal control of nutritive sucking pressure: evidence for an intrinsic $\tau$-guide," Experimental Brain Research, vol. 124, no. 3, pp. 371-382, 1999.

[7] E. Tamilia, F. Taffoni, D. Formica et al., “Technological solutions and main indices for the assessment of newborns' nutritive sucking: a review," Sensors, vol. 14, no. 1, pp. 634-658, 2014.

[8] V.S. Sakalidis and D. T. Geddes, "Suck-swallow-breathe dynamics in breastfed infants," Journal of Human Lactation, 2015.

[9] E. Schena, C. Massaroni, P. Saccomandi, and S. Cecchini, "Flow measurement in mechanical ventilation: a review," Medical Engineering \& Physics, vol. 37, no. 3, pp. 257-264, 2015.

[10] S. C. Tarrant, R. E. Ellis, F. C. Flack, and W. G. Selley, "Comparative review of techniques for recording respiratory events at rest and during deglutition," Dysphagia, vol. 12, no. 1, pp. 24-38, 1997.

[11] M. A. Qureshi, F. L. Vice, V. L. Taciak, J. F. Bosma, and I. H. Gewolb, "Changes in rhythmic suckle feeding patterns in term infants in the first month of life," Developmental Medicine and Child Neurology, vol. 44, no. 1, pp. 34-39, 2002.

[12] E. C. Goldfield, "A dynamical systems approach to infant oral feeding and dysphagia: from model system to therapeutic medical device," Ecological Psychology, vol. 19, no. 1, pp. 21-48, 2007.

[13] L. E. Al-Sayed, W. I. Schrank, and B. T. Thach, "Ventilatory sparing strategies and swallowing pattern during bottle feeding in human infants," Journal of Applied Physiology, vol. 77, no. 1, pp. 78-83, 1994.

[14] I. H. Gewolb, F. L. Vice, E. L. Schweitzer-Kenney, V. L. Taciak, and J. F. Bosma, "Developmental patterns of rhythmic suck and swallow in preterm infants," Developmental Medicine and Child Neurology, vol. 43, no. 1, pp. 22-27, 2001.

[15] I. H. Gewolb and F. L. Vice, "Maturational changes in the rhythms, patterning, and coordination of respiration and swallow during feeding in preterm and term infants," Developmental Medicine and Child Neurology, vol. 48, no. 7, pp. 589-594, 2006.

[16] M. Ciocchetti, C. Massaroni, P. Saccomandi et al., "Smart textile based on fiber bragg grating sensors for respiratory monitoring: design and preliminary trials," Biosensors, vol. 5, no. 3, pp. 602615, 2015.

[17] C. Cavaiola, E. Tamilia, C. Massaroni et al., "Design, development and experimental validation of a non-invasive device for recording respiratory events during bottle feeding," in Proceedings of the 36th Annual International Conference of the IEEE Engineering in Medicine and Biology Society (EMBC '14), pp. 2123-2126, Chicago, Ill, USA, August 2014.

[18] F. Taffoni, E. Tamilia, M. R. Palminteri et al., "Ecological sucking monitoring of newborns," IEEE Sensors Journal, vol. 13, no. 11, pp. 4561-4568, 2013.

[19] E. Tamilia, D. Formica, A. Scaini, and F. Taffoni, "An automated system for the analysis of newborns' oral-motor behavior," IEEE Transactions on Neural Systems and Rehabilitation Engineering, 2015.

[20] M. J. A. M. van Putten, M. H. P. M. van Putten, A. F. P. van Putten, J. C. Pompe, and H. A. Braining, "A silicon bidirectional flow sensor for measuring respiratory flow," IEEE Transactions on Biomedical Engineering, vol. 44, no. 2, pp. 205-208, 1997.

[21] E. Binu and N. S. Varsha, "Real time monitoring of respiratory parameters using a wireless portable system," International Journal of Engineering Development and Research, vol. 3, no. 1, pp. 283-287, 2014.

[22] P. Jiang, S. Zhao, and R. Zhu, "Smart sensing strip using monolithically integrated flexible flow sensor for noninvasively monitoring respiratory flow," Sensors, vol. 15, no. 12, pp. 3173831750, 2015.

[23] E. Schena and S. Silvestri, "A transistor based air flow transducer for thermohygrometric control of neonatal ventilatory applications," Review of Scientific Instruments, vol. 79, no. 10, Article ID 104301, 2008.

[24] M. Giorgino, G. Morbidoni, E. Tamilia, F. Taffoni, D. Formica, and E. Schena, "Design and characterization of a bidirectional, low cost flowmeter for neonatal ventilation," IEEE Sensors Journal, vol. 14, no. 12, pp. 4354-4360, 2014.

[25] T. Yamada, Y. Mori, K. Minami, K. Mishima, and Y. Tsukamoto, "Three dimensional analysis of facial morphology in normal Japanese children as control data for cleft surgery," The Cleft Palate-Craniofacial Journal, vol. 39, no. 5, pp. 517-526, 2008.

[26] J. E. White, A. F. Ayoub, M.-T. Hosey et al., "Three-dimensional facial characteristics of caucasian infants without cleft and correlation with body measurements," Cleft Palate-Craniofacial Journal, vol. 41, no. 6, pp. 593-602, 2004.

[27] G. Agnihotri and D. Singh, "Craniofacial anthropometry in newborns and infants," Iranian Journal of Pediatrics, vol. 17, pp. 87-94, 2007.

[28] C. D. Cook, J. M. Sutherland, S. Segal et al., "Studies of respiratory physiology in the newborn infant. III. Measurements of mechanics of respiration," The Journal of Clinical Investigation, vol. 36, no. 3, pp. 440-448, 1957.

[29] E. Schena, G. Lupi, S. Cecchini, and S. Silvestri, "Linearity dependence on oxygen fraction and gas temperature of a novel Fleisch pneumotachograph for neonatal ventilation at low flow rates," Measurement, vol. 45, no. 8, pp. 2064-2071, 2012. 
[30] G. Sabatino, E. Schena, S. Cecchini, and S. Silvestri, "Design and experimental characterization of a gas flow generator to calibrate flow meters for neonatal ventilation," in Proceedings of the 4th IEEE RAS/EMBS International Conference on Biomedical Robotics and Biomechatronics, pp. 309-313, IEEE, Roma, Italy, June 2012.

[31] K. C. L. Carlsen, P. Magnus, and K.-H. Carlsen, "Lung function by tidal breathing in awake healthy newborn infants," European Respiratory Journal, vol. 7, no. 9, pp. 1660-1668, 1994.

[32] JCGM, "Evaluation of measurement data. Guide to the expression of uncertainty in measurement," JCGM 100:2008, 2008.

[33] C. J. Willmott and K. Matsuura, "Advantages of the mean absolute error (MAE) over the root mean square error (RMSE) in assessing average model performance," Climate Research, vol. 30, no. 1, pp. 79-82, 2005.

[34] C. Lau, "Development of oral feeding skills in the preterm infant," in Handbook of Growth and Growth Monitoring in Health and Disease, V. R. Preedy, Ed., chapter 29, pp. 499-512, Springer, New York, NY, USA, 2012.

[35] K. Mizuno and A. Ueda, "The maturation and coordination of sucking, swallowing, and respiration in preterm infants," Journal of Pediatrics, vol. 142, no. 1, pp. 36-40, 2003.

[36] B. M. Wright and K. Callan, "A new respiratory recording and monitoring system," in Proceedings of the International Symposium on Ambulatory Monitoring, pp. 329-334, Belgium, 1980.

[37] D. W. Hill and A. M. Dolan, Intensive Care Instrumentation, Academic Press, London, UK, 1976.

[38] S. L. Wilson, B. T. Thach, R. T. Brouillette, and Y. K. Abu-Osba, "Coordination of breathing and swallowing in human infants," Journal of Applied Physiology Respiratory Environmental and Exercise Physiology, vol. 50, no. 4, pp. 851-858, 1981.

[39] Y.-L. Wang, J.-S. Hung, L.-Y. Wang et al., "Development of a wireless oral-feeding monitoring system for preterm infants," IEEE Journal of Biomedical and Health Informatics, vol. 19, no. 3, pp. 866-873, 2015.

[40] W. G. Selley, R. E. Ellis, F. C. Flack, and W. A. Brooks, "Coordination of sucking, swallowing and breathing in the newborn: its relationship to infant feeding and normal development," British Journal of Disorders of Communication, vol. 25, no. 3, pp. 311327, 1990.

[41] M. B. Hanlon, J. H. Tripp, R. E. Ellis, F. C. Flack, W. G. Selley, and H. J. Shoesmith, "Deglutition apnoea as indicator of maturation of suckle feeding in bottle-fed preterm infants," Developmental Medicine and Child Neurology, vol. 39, no. 8, pp. 534-542, 1997. 


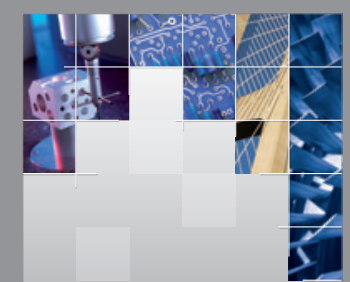

\section{Enfincering}
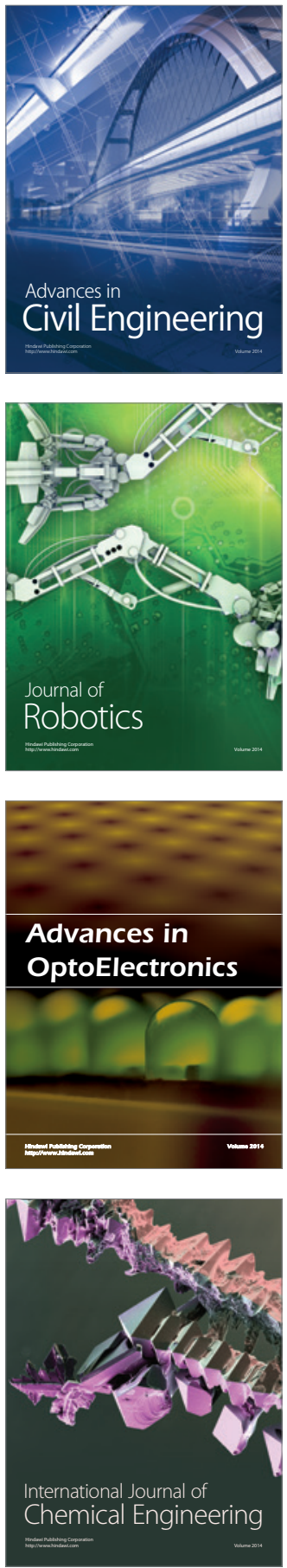

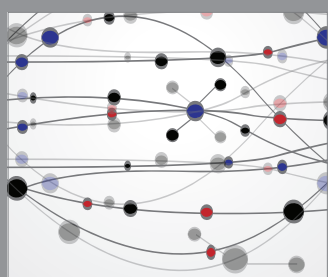

The Scientific World Journal

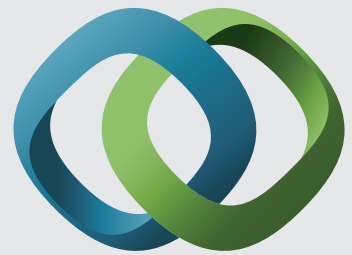

\section{Hindawi}

Submit your manuscripts at

http://www.hindawi.com
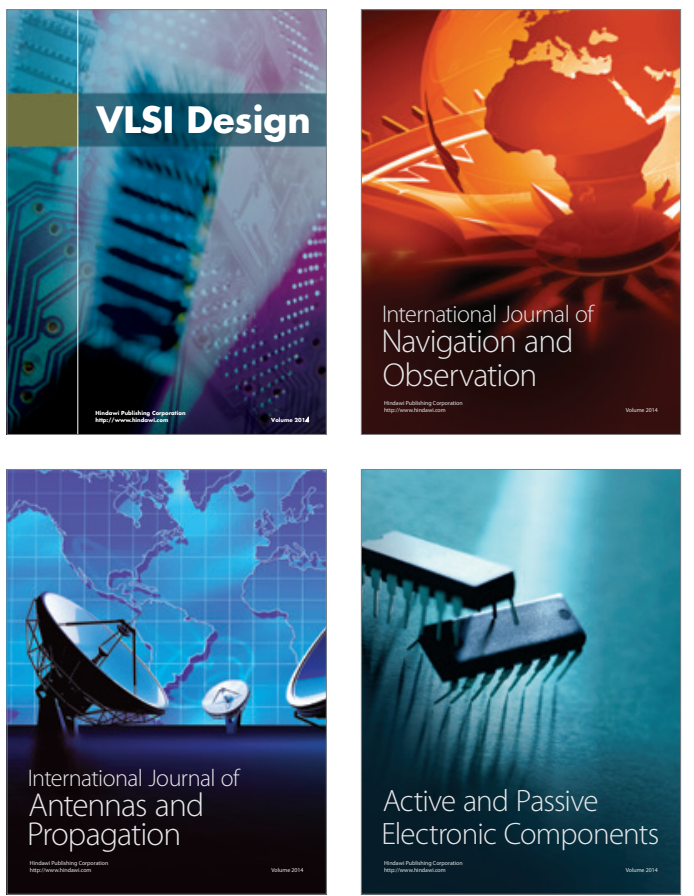
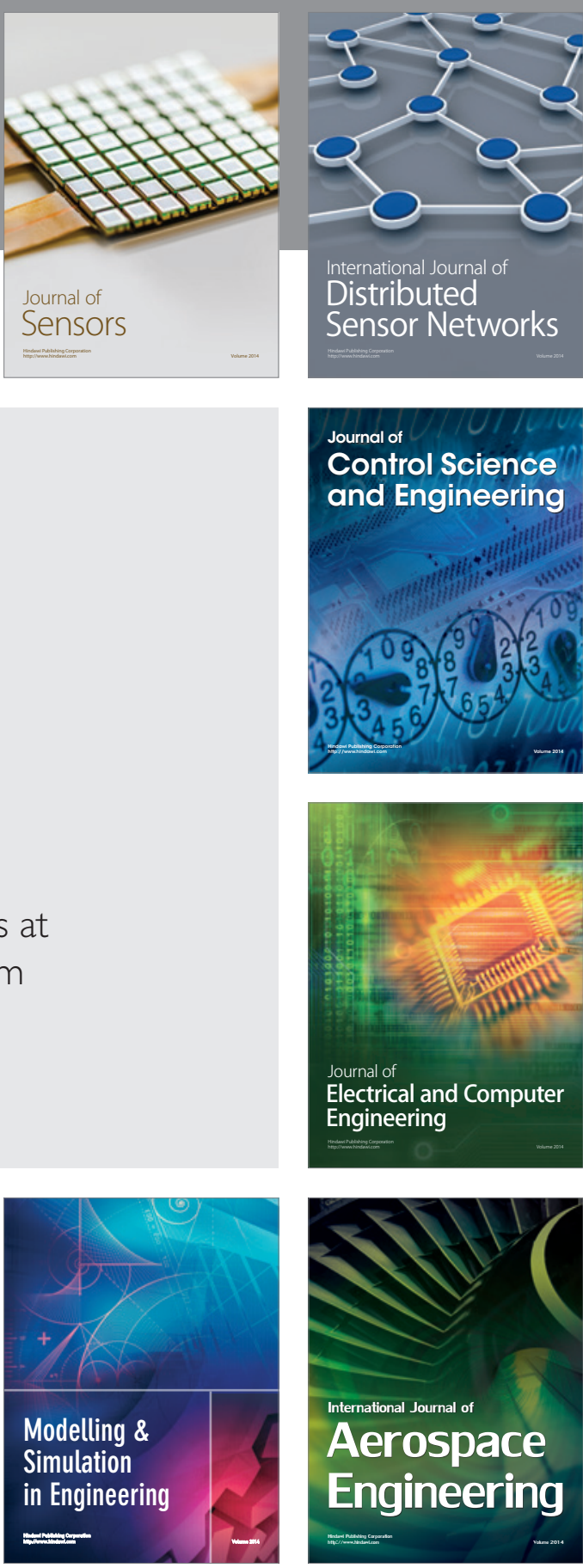

International Journal of

Distributed

Sensor Networks

Journal of

Control Science

and Engineering
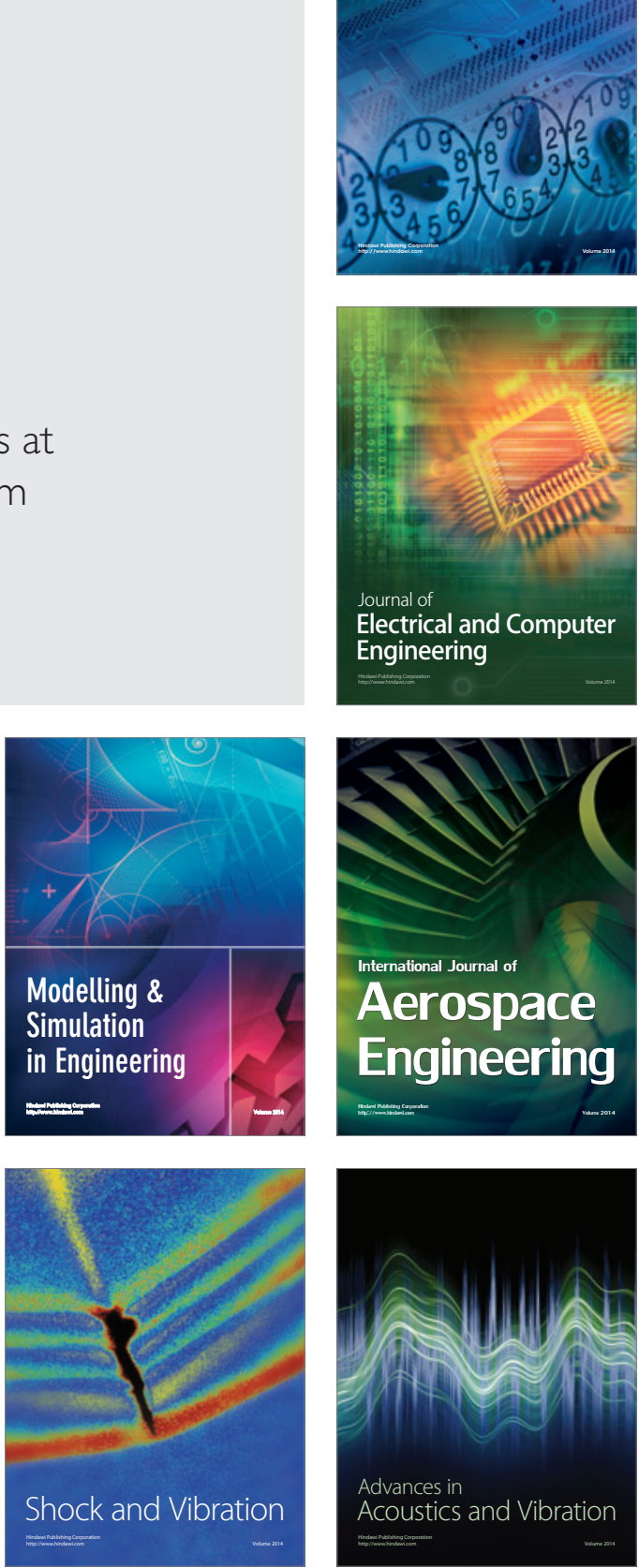